\title{
Paolo Tortonese, L'Cil de Platon et le regard romantique
}

\section{Rita Severi}

\section{Q OpenEdition}

1 Journals

\section{Edizione digitale}

URL: https://journals.openedition.org/studifrancesi/45972

DOI: 10.4000/studifrancesi.45972

ISSN: 2421-5856

\section{Editore}

Rosenberg \& Sellier

\section{Edizione cartacea}

Data di pubblicazione: 1 octobre 2007

Paginazione: 455-456

ISSN: 0039-2944

\section{Notizia bibliografica digitale}

Rita Severi, «Paolo Tortonese, L'EFil de Platon et le regard romantique», Studi Francesi [Online], 152 (LI I

II) | 2007, online dal 30 novembre 2015, consultato il 24 novembre 2021. URL: http://

journals.openedition.org/studifrancesi/45972 ; DOI: https://doi.org/10.4000/studifrancesi.45972

Questo documento è stato generato automaticamente il 24 novembre 2021.

\section{(c) (i) $\odot$}

Studi Francesi è distribuita con Licenza Creative Commons Attribuzione - Non commerciale - Non opere derivate 4.0 Internazionale. 


\title{
Paolo Tortonese, L'Cil de Platon et le regard romantique
}

\author{
Rita Severi
}

\section{NOTIZIA}

PAOLO TORTONESE, L'Æil de Platon et le regard romantique, Paris, Éditions Kimé, 2006, pp. 242.

1 Nell'introduzione l'autore ci avverte che l'idea di compiere uno studio sulla metafora platonica dell'«occhio dell'anima, che era rimasto sepolto nel fango barbarico» (Resp. 533D) gli venne leggendo Ernst Robert Curtius, Letteratura europea e Medio Evo latino (Firenze, La Nuova Italia, 1992, in particolare, p. 156), il quale, dedicando un intero capitolo alla trasmissione delle metafore, si sofferma su quelle corporali. L'occhio dell'anima, riassume Curtius, «ha goduto largo favore presso gli autori, sia pagani sia ecclesiastici» (p. 157). Paolo Tortonese si spinge molto oltre, in quanto esplora la contestualizzazione e le valenze della metafora platonica nel periodo romantico europeo attraverso gli esempi scelti dall'estetica di Schelling, Coleridge e Joubert. Verifica il processo storico di trasmissione dell'immagine, della sua connotazione cristiana, attraverso svariati testi, da Agostino ai Padri della Chiesa a Marsilio Ficino, per poi valutare il paradigma platonico nelle opere dei grandi autori romantici francesi, soprattutto Balzac e Hugo.

2 Nella letteratura romantica la diffusione della metafora dello sguardo interiore è molto frequente. Esempi tratti dai romanzi d'appendice di Sue, dalla poesia di Victor Hugo, dagli scritti di Joseph Joubert, che esplicitamente invita l'artista a chiudere gli occhi e vedere, vengono riportati dall'autore. Espressioni come «l'occhio dello spirito, l'occhio dell'anima, l'occhio interiore» si trovano in moltissimi scrittori francesi (Lamennais, Baudelaire, Guèrin, Balzac, e Gautier), inglesi (Shelley, Wordsworth e Coleridge) e tedeschi (Novalis, Schelling, i fratelli Schlegel) e rivelano, come dice Tortonese, la radice platonica, riconducibile ai passi del Sofista (254a) e della Repubblica (518c), dove il filosofo introduce la metafora degli «occhi dell'anima», organi dotati di una visione 
ultrasensibile, uno sguardo che attraversa lo schermo del mondo per attingere alle verità supreme. Gli scrittori romantici, dunque, fanno ricorso alle immagini platoniche per descrivere la complessità della loro visione del mondo, una gnoseologia che include spesso la metafora dello specchio, del terzo occhio, quello divino, della reminiscenza dell'anima innocente, come è ben evidente nella poesia di William Wordsworth (Ode on Intimations of Immortality, $1802 \mathrm{e}$ The World Is Too Much With Us, 1807).

3 La trasmissione diacronica della metafora platonica, secondo gli studi di Panofsky e Cassirer, lucidamente analizzati dallo studioso, ha subito perlomeno due importanti fasi di passaggio: la prima attraverso l'opera di Cicerone, il quale utilizzando le teorie sull'arte di Platone le tradisce per fondare, secondo Panofsky, una critica estetica; la seconda attraverso gli scritti di Plotino il quale ritiene che il mondo sensibile sia propedeutico a quello iperuranico. È lo stesso Plotino che consiglia di tornare allo "sguardo interiore», non come Narciso che si lasciò catturare dalla sua stessa immagine, ma come Ulisse che, davanti a Circe, guardò nella sua anima che anelava il ritorno in patria. Lo studioso passa ad analizzare la cristianizzazione dell'idea platonica negli scritti di san Agostino, il quale legge Platone attraverso procedimenti anagogici e allegorici per assimilarli alla rivelazione teologica, per poi soffermarsi sui testi ermetici di Marsilio Ficino, di Niccolò Cusano e, per brevi cenni, all'opera del grande teorico dell'arte manierista, il milanese Giovan Paolo Lomazzo.

Dopo aver presentato la documentazione diacronica della trasmissione del concetto filosofico, l'autore prende in considerazione alcuni autori romantici nel contesto europeo. In prima istanza egli si concentra sul saggio a tre voci di Friedrich Schelling, Bruno oder über das göttliche und natürliche Prinzip der Dinge (1802), dove il filosofo fa discutere i suoi personaggi sui concetti di verità e bellezza, tanto cari anche agli autori inglesi (per esempio, Keats, Ode on a Grecian Urn). Secondariamente, considera alcuni scritti di Samuel Taylor Coleridge, il quale, nel saggio, The Friend, dimostra come l'«inward eye» (si veda la famosa poesia I Wandered Lonely as a Cloud dell'amico William Wordsworth) distingue l'uomo dalle bestie. Ma questa non è che una delle espressioni platoniche che costellano i testi del poeta inglese, il quale, sin dal 1791 aveva iniziato ad approfondire i testi dei grandi autori platonici, da Plotino, a Ficino, a Giordano Bruno per poi inoltrarsi nelle esaltanti letture di Spinoza e Jacob Boehme, per approdare a Kant, Fiche e Schelling (pp. 127-128). Il poeta s'interroga sull'intelligibilità delle parole stesse, sul rapporto tra linguaggio e rappresentazione: le parole sono comprensibili per se stesse o sono state fissate nell'anima ai colui che le ascolta e si attivano ogni volta che vengono pronunciate? L'immagine poetica diventa per Coleridge il veicolo ideale della reminiscenza. Il terzo autore del quale Tortonese esamina i principi teorici è Joseph Joubert, il quale nei suoi Carnets inventa il neologismo «invidence» per esprimere «l'évidence intérieure intime» (p. 150), ovvero la concezione ossimorica della fusione di interiorità e apparenza.

Il paradigma di Joubert, che assimila l'anima all'occhio e l'intuizione alla vista, si riscontra, con elaborazioni originali, sia nella poesia di Hugo che nei romanzi di Balzac. La pupilla come anima è una similitudine frequente nella poesia di Hugo. La pupilla che contempla l'abisso o il «mur vertigineux» (p. 174) assume il significato della meditazione sull'infinito nella sua poetica, dove l'occhio interiore percepisce la rivelazione solo quando l'anima è éperdue, travolta, spaesata. Nelle opere di Balzac la vita anteriore affiora attraverso molteplici esperienze, dalla contemplazione della natura, allo sconvolgimento apportato dall'amore, dallo spaesamento del viaggio, 
all'epifania che si manifesta nella meditazione artistica. Le metafore platoniche associate all'occhio dell'anima, alla duplicità tra anima e corpo o spirito e materia, assumono un rilievo assoluto. Balzac definisce la vista e l'occhio «gaine», guaine, come se gli organi fossero spade, avvolte in contenitori o rivestimenti che la volontà individuale può scartare, svelare. Così l'anima e il corpo appaiono associati come contenuto e contenitore. Balzac, che annota in un suo cahier «Ô Platon, sublime corrupteur qui fait de l'âme un instrument pour ouvrir un corps, tandis qu'il est si naturel d'ouvrir le corps pour y trouver l'âme» (p. 202), tende a snaturare la metafora platonica dell'occhio dell'anima e a considerarla, anche alla luce delle nuove scoperte scientifiche, non più come l'immagine o rappresentazione della ricerca metafisica, ma piuttosto come scoperta materiale. Da Balzac in avanti il corpo (nella letteratura e nella vita) assume sempre più peso fino a diventare un elemento dominante nell'epoca contemporanea. Attraverso l'analisi della metafora platonica ci si accorge che la distanza tra il mondo di Honoré de Balzac e il mondo di uno dei suoi più attenti lettori, Oscar Wilde ne The Picture of Dorian Gray (1891), in relazione alla dicotomia tra anima e corpo, è veramente breve.

Il saggio di Paolo Tortonese, che si può inscrivere nell'ambito della critica della cultura estetica o delle idee, è chiaro, ben scritto e documentato, con una bibliografia aggiornata e un accurato indice finale. 